ISBN 978-81-933894-6-1

7th International Conference on Recent Trends in Science, Engineering and Technology

(RTSET-2017)

London (U K) June 29-30, 2017

\title{
Goal Directed Supplier Selection Model: An Agent-Based Architecture
}

\author{
Ercan Öztemel ${ }^{1}$, Banu Çalış Uslu ${ }^{2}$ \\ ${ }^{1}$ Industrial Engineering Department- Marmara University Turkey \\ ${ }^{2}$ MERI-Sheffield Hallam University UK
}

\begin{abstract}
The aim of this study is to develop a supplier selection model on the basis of an Agent Based System in order to assure that the pre-defined goals are fulfilled. To develop the proposed supplier model with measurement capability, primarily a Supplier Agent Architecture was designed, and integration between raw materials and suppliers were assured in accordance with this architecture. The model is formulated by means of a Mathematical Model with a set of weights determined according to Analytic Hierarchy Process. Finally, proposed model is employed in JAVA-based software environment. For the case study, data were taken from real cabinet manufacturing company in Turkey. The results of the implementation clearly indicated that the purchasing costs are decreased. In addition, the result of the study highlighted that the ability to measure of pre-defined goals are possible.
\end{abstract}

Keywords: Agent, Agent-based Systems, Supplier Selection, Manufacturing Systems

\section{Introduction}

Supplier selection is a key operational task of the most crucial logistics decision in any Supply Chain Management System. Choosing the right suppliers significantly increases the corporate competitiveness, while significantly reducing the purchasing costs.

De Boer et al. [1] described the supplier selection process as a selection of most suitable suppliers which can deliver the most suitable products at the right time with right quality and in the right price. Various approaches have been used to find right suppliers among various alternatives according to set criteria such as cost, quality, delivery time or similar ones. These are highly dependent on the specific requirements of product, management strategy of company and organizational behavior of the system.

For this reason, the determination of criteria requires analysis, judgment and assessment by domain experts. Note that, there is a need for software programs to collect and analyze data for determining the most important criteria. This software should also be designed to provide information flow between supplier and companies in order to create the most suitable supplier evaluation mechanism. This capability can be ensured using an agent based architecture with intelligent capabilities. Since, intelligent and autonomous systems are considered to be well known for their capability to provide solutions to any kind of selection and assessment, this study aimed utilizing intelligent agents in supplier selection problem with related requirements.

Wooldridge and Jennings [2] defined an agent as: 'a computer system that is situated in some environment, in which it is capable of autonomous action, in order to meet its predefined objectives'. Multi agent systems (MASs), 
on the other hand, can be defined as highly interactive agents working collectively through collaboration or competition to solve problems by using their individual capabilities [3].

The use of intelligent software agents for supply chain management has been studied by several researchers [see for examples, Swaminathan et al., [4] ; Caridi et al., [5]; Chan and Chan, [6]; Nissen et al., [7]]. The MASs are alternative technologies for automated decisions and coordination in supply networks because of the certain features such as distribution, collaboration, autonomy, and intelligence [8].

Considering the agent based architectures in supplier selection, the literature also provides a wide variety of research including Kim and Cho, [9]; Wang et al., [10]; Wang, Wong, and Wang, [11]; Wong and Fang, [12]. Some studies concentrates especially on adaptive negotiation strategy (see for examples, Fang \& Wong, [13]; Wang et al., [14]; Yu et al., [15].

Moreover, He et al [16] studied an agent based retail model, Russ and Walz [17] purposed the multi-agent supply chain simulation framework MACSIMA, Akanle and Zhang [18] showed an iterative bidding mechanism in order to satisfy optimum resource combination.

In this study new shed light on agent-based computational experiment for supplier selection mechanism, and a case study are proposed. The contribution of this paper to supplier knowledge is a well-defined goal based selection process which is measurable and adaptable. Chapter II introduces the proposed model. The application of the proposed model is given in Chapter III. The paper ends with a conclusion including future work.

\section{Proposed Model}

This model is designed to handle relationship between supplier and raw materials in a certain manufacturing system in order to support the assessment with respect to whether pre-defined goals are satisfied or not. Main motivations behind the proposed model are;

1. Ability to integrate (Specific Purpose - integrating the raw materials to the related suppliers)

2. Ability to measure (Specific Purpose - measuring the performance of the purchased raw materials)

3. Ability to self-organize (Reactiveness - ability to establish basic rules for the interactions between the Supplier model and the system)

4. Ability to adapt (Social Ability - ability to adapt over time in response to changes in the environment of the Supplier Model)

5. Ability to control (Autonomy - ability to control of supplier selection mechanism of the system to purchase needed raw materials)

\subsection{Proposed Agent Architecture}

In order to establish the Supplier Model with the capability to measure, a Supplier Agent Architecture is designed as shown in Figure 1. Note that the Supplier Model with related agents is a part of an integrated manufacturing environment including product, quality, machine, and accounting agents. This paper focuses the attention only on the supplier agents as explained below.

Note that, the proposed Supplier Model consist of four agents, namely; Material Requirements Agent, Procurement Agent, Buyer Agent, and Order Organizer Agent.

\subsubsection{Order Organizer Agent}

It is responsible to check the order list. If there is any update on the list, this agent calculates the total number of products to be produced and sends them to Material Requirement Agent for planning the required material. 


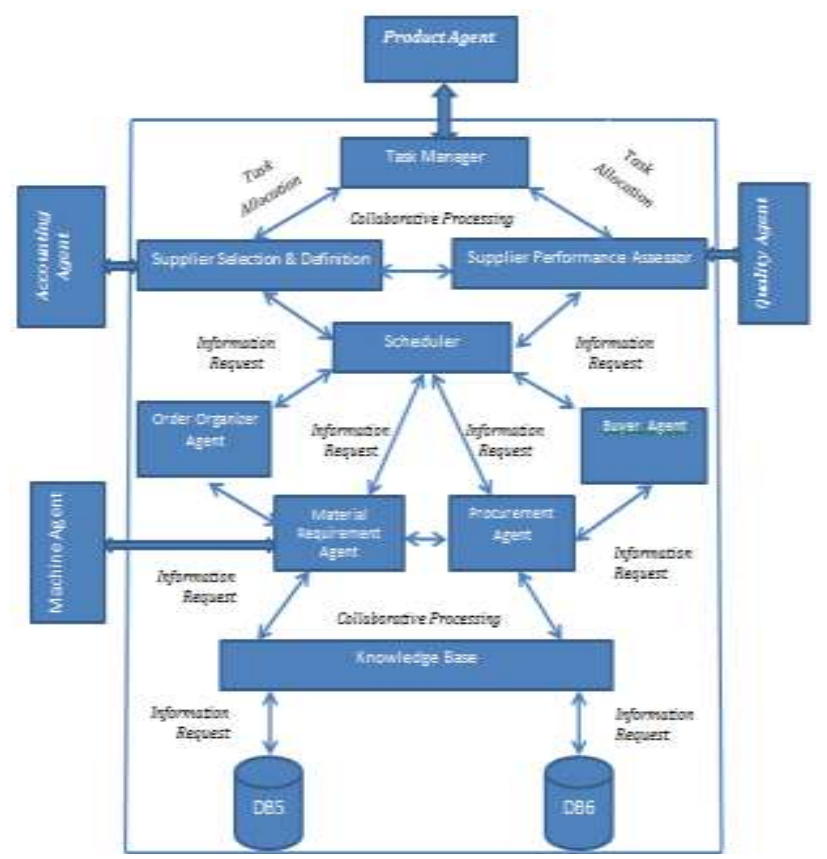

Fig. 1: Proposed Agent Architecture

\subsubsection{Material Requirement Agent}

It calculates material requirements in accordance with the bill of materials (BOM) and list of the products. It then searches for the available suppliers of those. After identifying the characteristics of possible suppliers, this agent prepares a purchase order for the Procurement Agent. Available suppliers are those which can deliver in the raw materials before the time of manufacturing (lead time). The following formula has been used to make this decision.

$$
A S q=T_{i, o}-\left(T_{t}+T_{r, q}+T_{i, m}\right)
$$

Where;

$\mathrm{AS}_{\mathrm{q}}$ is Available Supplier q

$\mathrm{T}_{\mathrm{i}, \mathrm{o}}$ is due date of product $\mathrm{i}$ of order $\mathrm{o}$

$\mathrm{T}_{\mathrm{t}}$ is current time

$\mathrm{T}_{\mathrm{r}, \mathrm{q}}$ is delivery time of raw materials $\mathrm{r}$ from supplier $\mathrm{q}$

$\mathrm{T}_{\mathrm{i}, \mathrm{m}}$ is manufacturing time $\mathrm{m}$ of product $\mathrm{i}$

\subsubsection{Procurement Agent}

It searches possible suppliers for each units of raw materials and select one of them. It eliminates the suppliers which could not deliver the products on time. Note that each available supplier has a positive idle time value calculate as;

\section{Idle Time $=$ Order date $-($ processing time + delivery time $)$}

The main objective of this agent is to avoid the manufacturing delay caused by the shortcoming of goods. If none of the suppliers is not able to provide the material on time, than the agent sends a message to the user to search for a new supplier or a compromise strategy is implemented. Once the lists of available suppliers are generated, then the agent starts a selection process by the following process. Note that, if there is only a single supplier on the list, then no selection is employed. The supplier in the list is directly recommended.

For performing the selection, the procurement agent calculates a quality value for each available supplier depending on 3 main criteria; 
- correct raw material percentage,

- correct received unit percentage and

- correct shipment percentage.

These percentage values of suppliers are provided by the Quality Agent and average quality value of each supplier is calculated as the following;

From the Accounting Agent, the supplier price and payment terms are requested. Weights of the selection criteria is defined for the goods to be purchased using Analytical Hierarchy Process (AHP) which is one of the well-known and most commonly used decision making approach to determination of priority and grading of entities. The basic structure of AHP is shown in Figure 2. A generic form of AHP matrix is given in Figure 3, where w denotes the weight of each criteria. 1-5 scales were used in this study (see Taha, 2007).

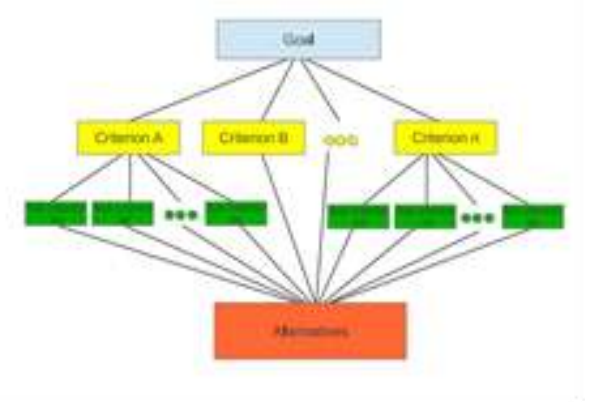

Fig. 2: A Generic Hierarchy of AHP (Klutho, 2013)

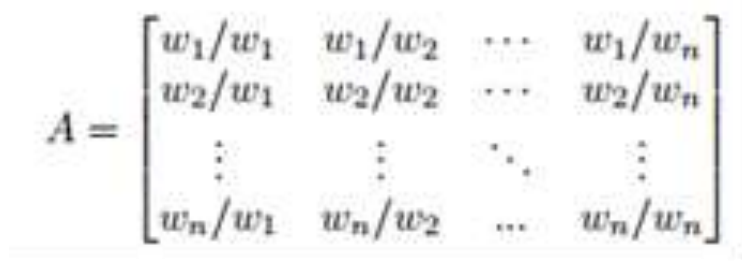

Fig 3: A generic Matrices of AHP (Klutho, 2013)

The weight values obtained is placed in a utility function to find the best supplier that satisfies the desired purpose. In this study, the utility function is named as PQPT value (P: Payment Q: Quality and PT: Payment Term) is designed as given in Equation 3. The utility value of the each supplier is recorded them in information system. Suppose ${ }^{P_{q}^{r}}$ represents the unit price of raw material $\mathrm{r}$ of supplier q, $Q_{q}^{r}$ denotes the quality value for raw material $\mathrm{r}$ of supplier q, ${ }^{P T_{q}}$ is payment term of supplier q. Then the Supplier Utility function is;

$$
P Q P T q, r=1 / P_{q}^{r} * w 1+Q_{q}^{r} * w 2+P T_{q} * w 3
$$

In this study, payment terms are assumed to be equal foreach product which is supplied by the same supplier . Structural frame code of supplier measurement function $\mathrm{f}_{\mathrm{q}, \mathrm{ts}, \mathrm{t}}$ is designed as given in Figure 4.

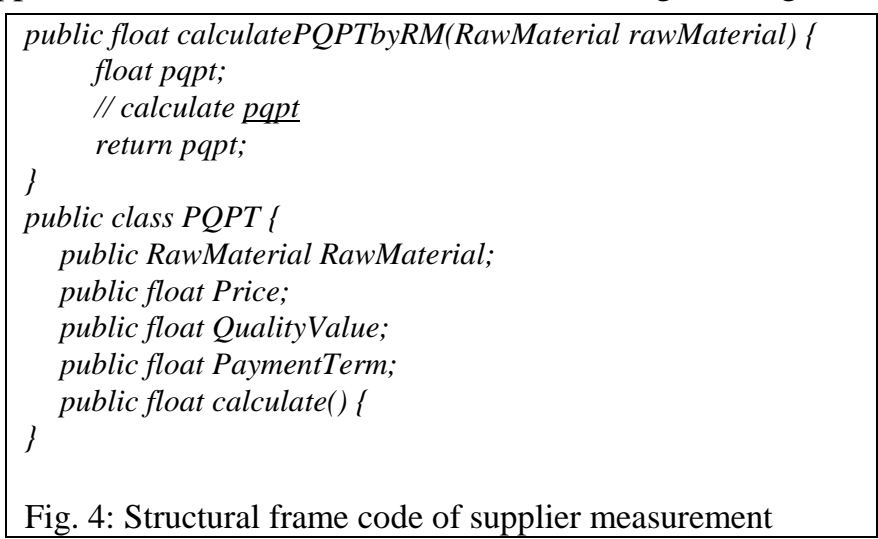

After calculating PQPT values of all available suppliers, this information is sent to the Buyer Agent. 


\subsubsection{Buyer Agent}

It receives the supplier opportunity cost report from Supplier Performance Assessor and suppliers PQPT list. It starts the bargaining process between suppliers. The following rules are implemented.

1. For suppliers with equal payment term value, the Buyer Agent selects the supplier which has highest PQPT value;

2. For the different payment terms then the agent selects the supplier which has the highest Opportunity cost which is explained below and provided by the Supplier Performance Assessor

3. It selects most appropriate supplier for the Purchasing and the agent sends a report to Supplier Performance Assessor.

After the agent architecture of the model is created, then design architecture of the proposed model is developed to satisfy the motivation of the proposed model.

\subsection{Design Architecture of the Proposed Model}

In order to satisfy model motivations listed above, the following components are generated within the architecture.

\subsubsection{Supplier Selection and Definition}

Module primarily creates a "supplier card" for each supplier and stores the related information of each raw material supplied.

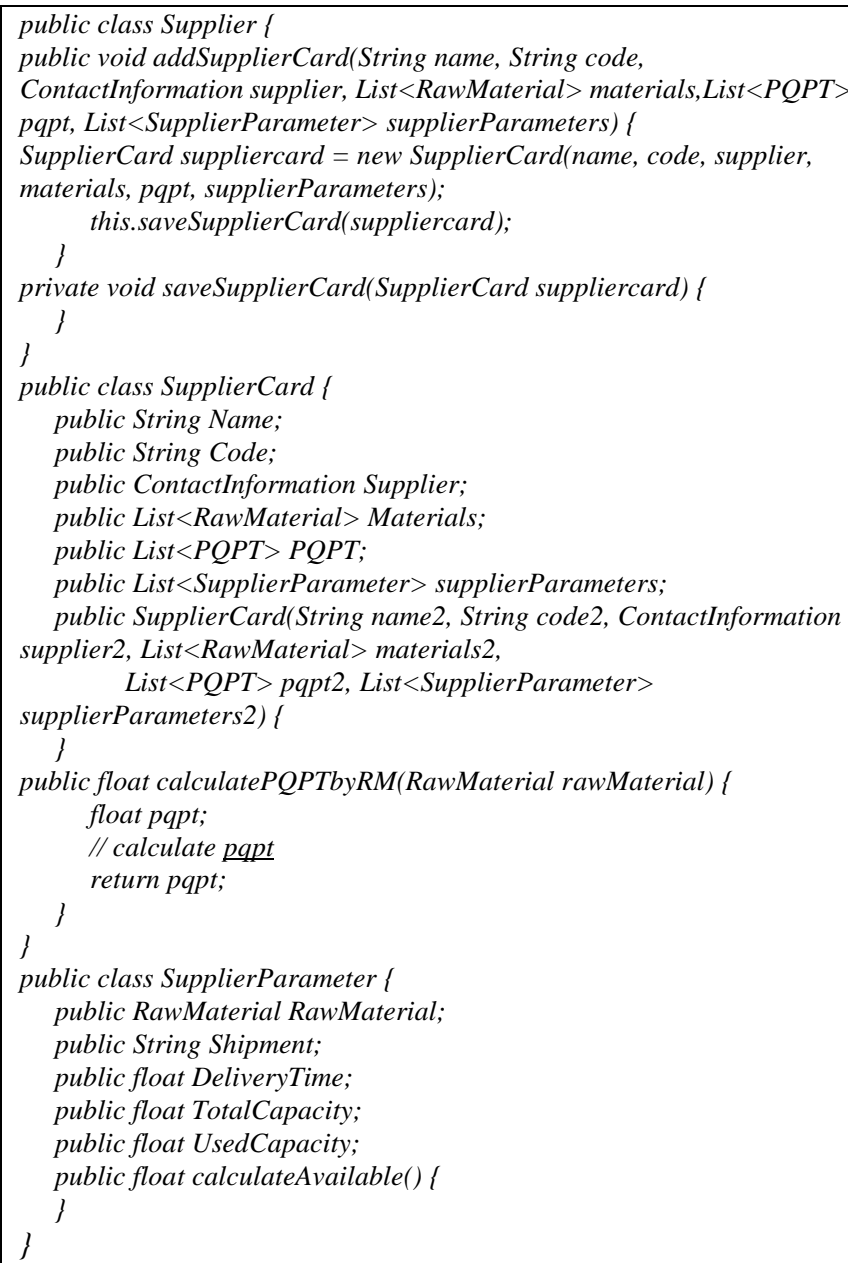

Fig. 5: Structural frame code of the Supplier Card 
This is required for the sake of sustaining the integration. The content of the supplier card is provided in Appendix A. In other words, integration between raw materials and suppliers are satisfied by means of supplier cards. The Structural frame code of the Supplier Card function which is denoted as $\mathrm{f}_{\mathrm{p}, \mathrm{t} s, \mathrm{t}}^{\mathrm{prd}}$ is given Figure 5.

\subsubsection{Supplier Performance Assessor}

Module is designed for measuring the purchasing performance using a mathematical model. This provides the ability to measure the goodness of the suppliers. Suppose;

$\mathrm{f}(\mathrm{SA})=$

$\left\{P t_{q}^{S}, A_{q}^{S}, Q_{q, d r}^{S}, \mathrm{f}_{\mathrm{q}, \mathrm{st}, \mathrm{t}}^{\mathrm{SD}}, \mathrm{f}_{\mathrm{q}, \mathrm{ts}, \mathrm{t}}^{\mathrm{SPm}}, \mathrm{SSS}_{\mathrm{q}}, \in_{\mathrm{q}}^{S}\right\}$

denotes the function set of the Supplier Model,

where;

- $P t_{q}^{5}$ set of percept of supplier $\mathrm{q}$,

- $A_{q}^{s}$ set of actions of supplier q,

- $u_{\text {q }}^{2}$ set of defect rate dr of supplier q,

- $\cos _{\mathrm{q} a \mathrm{a}}^{\mathrm{m}}$ denotes the Supplier card definition function task ts of supplier q, at time $\mathrm{t}$,

- $\mathrm{f}_{\mathrm{q}, \mathrm{ts}, \mathrm{t}}^{\mathrm{Spm}}$ is performance measurement function task ts of supplier $\mathrm{q}$, at time $\mathrm{t}$,

-, $\mathrm{SSS}_{\mathrm{q}}$ denotes the system states of the Supplier Agent and

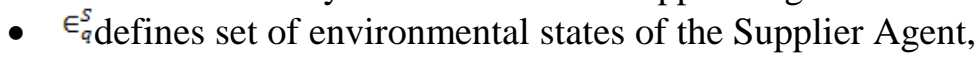

Total success factor of the suppliers (indicated by Z) is calculated as;

$$
\operatorname{Max} Z_{s}=\operatorname{avg}\left(\sum_{q, r m}^{s}\left(R M_{q, r m, p q p t}\right)\right)
$$

where, $\boldsymbol{R M}_{\text {rm,pqut }}$ refers the PQPT value of raw material rm purchased from supplier q. And average, PQPT value is assumed as success rate of supplier q. In similar way, equation 5 is designed for the negotiation process between PQPT value and Opportunity Cost.

$$
\mathrm{OC}_{\mathbf{r}, \mathbf{q}}=P_{q}^{r} * \mathrm{TQ}_{\mathbf{r}} *[1+(\text { interest rate/100) }] \mathbf{t}
$$

where;

- $P_{q}^{r}$ represents the unit price of raw material $r$ of supplier $\mathrm{q}$

- TQr denotes the total need of the raw material $r$

- $\mathrm{t}$ refers the payment term

- OCr,q is opportunity cost for raw material $r$ to be purchased from that supplier $q$

This calculation is especially important for making selections among the suppliers with equal $\mathrm{P}$ values. As keeping the cash capital for a while provides extra profit. Structural frame code of supplier measurement function $\mathrm{f}_{\mathrm{g}, t \rightarrow, t}^{\mathrm{Spm}}$ is provided in Figure 6.

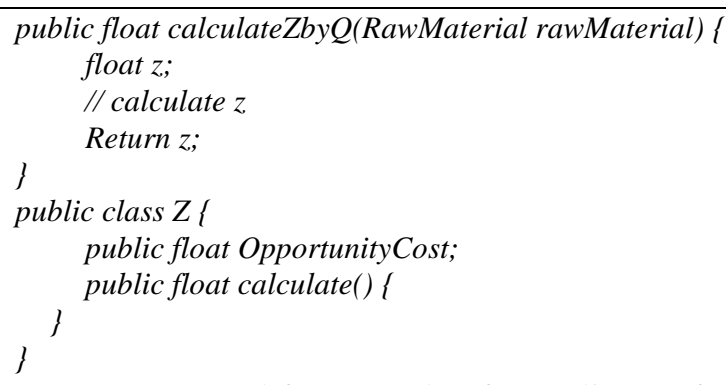

Fig. 6: Structural frame code of Supplier performance Assessor

After calculating the Opportunity Cost, this information is sent to the Buyer Agent to decide on necessary procurement. When there is a new purchase, the related new supplier success value is recorded in Database. 


\subsubsection{Task Manager}

It is designed to allocate the tasks. It enables system administrators to update the related information which includes system dynamics (beliefs, desires, rules, etc.). These dynamics give the model an ability to establish basic rules for the interactions and satisfy self-organizing capability.

In order to establish self-organizing capability; the business rules, which will ensure information flow was created. The information flow between agents is shown in Figure 7.

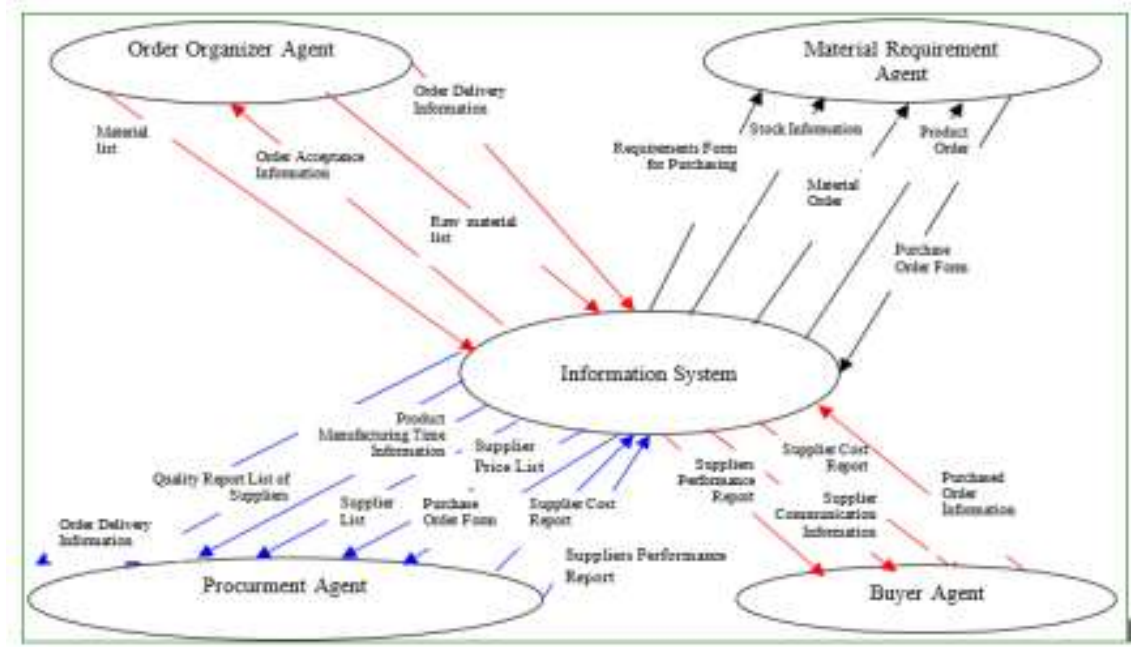

Fig. 7: Proposed Supplier Model Information Flow

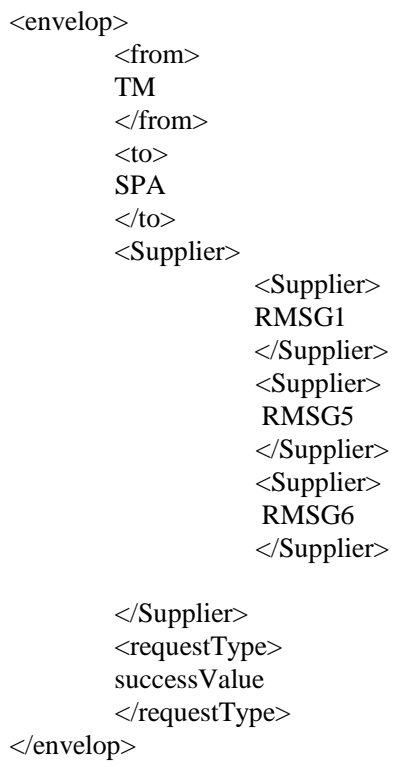

Fig. 8: An example request from TM -> SPA (Task Manager to Performance Assessor)

Some of the pre-defined business rules are listed below;

- Supplier success defines the intervention of the decrease in performance of the supplier by means of the supplier success.

-A relationship between raw-material/material with Supplier is to be set

- To prevent shortcoming of the goods, idle time calculation is to be done

- By using AHP, weights of the each criteria (price, quality, and odor measurement) is to be defined 
-Supplier PQPT (price, quality and payment) value of each Supplier (read Procurement agent working principle) is to be calculated.

- For the equal PQPT values, opportunity cost value is to be calculated to select most appropriate supplier

- The supplier s the most appropriate on when PQPT value or opportunity cost is the most suitable

- After each new procurement, new success level of each supplier is to be calculated

Similarly, the KQML message standard and XML is selected for Agent Communication Language. One of the applied XML structure is illustrated in Figure 8 for the Supplier success measurement task event of Supplier 1.

\subsubsection{The Scheduler}

It responsible for both satisfying the adaptation of the model-based intelligent design system, and control of the activities within the model. These are being explained respectively.

Ability to adapt: An example adaptation rule of the Supplier Agent is pre-defined and given in Figure 9.

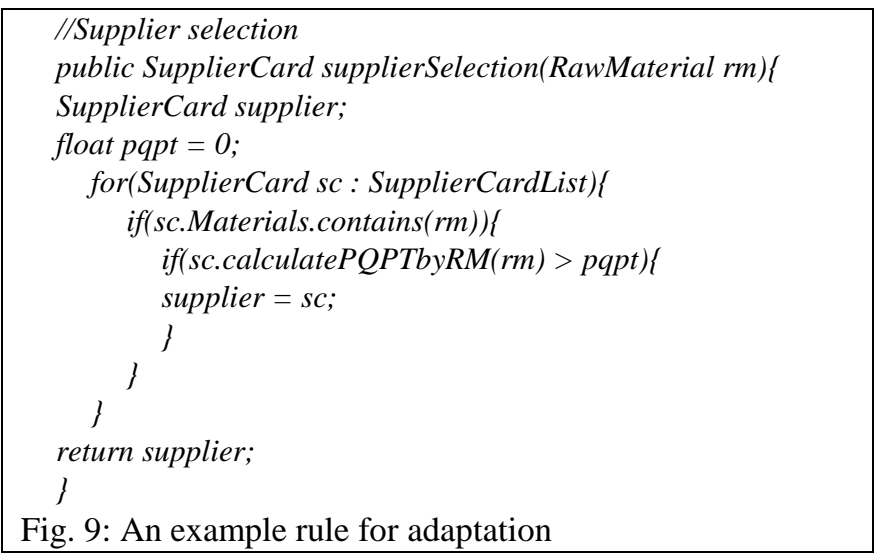

After every production process completed, when the stock level of any raw material being used is decreased below the minimum stock level, the process of supplier selection is started. It takes process information from the system, checks for needs and sends this information to Material Requirement Agent. In addition, this model controls the activities in the model by means of a precedence relation given Figure 10 below.

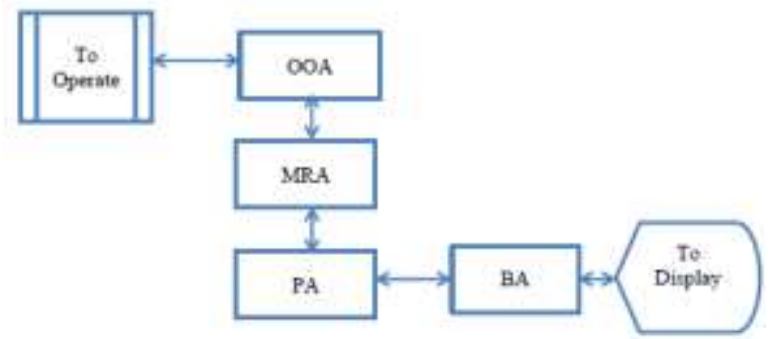

Fig. 10: Precedence rule in the proposed model.

\section{Case Study}

A prototype case study is implemented in a real manufacturing company located in Istanbul, Turkey. It manufactures cabin products and markets these products to many different countries of the world. Due to the sensitivity of the information used and the competitiveness, the name of the company is intentionally named as $\mathrm{ABC}$. The applying the proposed system in $\mathrm{ABC}$ is explained step by step below. 
Step 1: The data about the suppliers of the company were collected in order to generate respective supplier cards (see Appendix A). Then, weights of each criteria are determined by the experts using AHP (see Table 1)

TABLE 1: AHP matrix (P-price, Q-quality, and PT- payment term)

\begin{tabular}{|l|l|l|l|}
\hline & $\mathrm{P}$ & $\mathrm{Q}$ & $\mathrm{PT}$ \\
\hline $\mathrm{P}$ & 1 & 4 & 3 \\
\hline $\mathrm{Q}$ & 0.25 & 1 & 3 \\
\hline $\mathrm{PT}$ & 0.33 & 0.33 & 1 \\
\hline
\end{tabular}

A normalized matrix was built and relative weights are gathered as shown in Table II.

TABLE II: AHP normalized matrix

\begin{tabular}{|l|l|l|l|l|}
\hline & P & Q & PT & W \\
\hline P & 0.63 & 0.75 & 0.43 & $\mathbf{0 . 6 0}$ \\
\hline Q & 0.16 & 0.19 & 0.43 & $\mathbf{0 . 2 6}$ \\
\hline PT & 0.21 & 0.06 & 0.14 & $\mathbf{0 . 1 4}$ \\
\hline
\end{tabular}

For the detail information on calculation of normalized matrix see Taha [19].

Step 2: The payment dates of the company were categorized in accordance with the view of experts as the following;

i. " 0 " for suppliers who demand cash on delivery

ii. " 1 " for suppliers who demand payment after 30 days from delivery

iii. "2" for suppliers who demand payment after 60 days from delivery

iv. "3" for suppliers who demand payment after 90 days from delivery

For calculating the utility function; $\mathrm{PQPT}_{6,1}$ denotes the utility function value of supplier 6 for raw material say, $\mathrm{h}_{1}$

i.Price / Lot (TL) of $h_{1}$ is 1.3 TL (TL: Turkish Lira)

ii. Quality value of Supplier 6 is $59 \%$ (can be seen in Table 3)

iii.Payment Term of the Supplier 6 is 3.

iv. Total need (from production order) is assumed as 350

Utility Function of supplier 6 for the raw material type h1 is calculated as;

$\left(\mathrm{PQPT}_{6,1}\right)=(1 /(0.63 * 1.3))+0.26 * 59+0.14 * 3=17.04$

Step 3: A database for the quality levels of the suppliers of the company was created and defined in the software. Table III shows a part of the table prepared to measure suppliers' quality levels. The table shows that the quality success levels of suppliers which can supply $\mathrm{h}_{1}$.

TABLE III: A part of quality success levels of suppliers

\begin{tabular}{|c|c|c|c|c|c|c|c|c|c|c|}
\hline Suppliers & $\begin{array}{l}\text { Number } \\
\text { of Raw } \\
\text { Material } \\
\text { Type }\end{array}$ & $\begin{array}{l}\text { Number } \\
\text { of fault } \\
\text { Raw } \\
\text { Material } \\
\text { Type }\end{array}$ & $\begin{array}{l}\text { Correct } \\
\text { Raw } \\
\text { material } \\
\text { percentage }\end{array}$ & $\begin{array}{l}\text { Received } \\
\text { Raw } \\
\text { Material }\end{array}$ & $\begin{array}{l}\text { Fault } \\
\text { Raw } \\
\text { Material }\end{array}$ & $\begin{array}{l}\text { Correct } \\
\text { Received } \\
\text { unit } \\
\text { percentage }\end{array}$ & $\begin{array}{l}\text { Number } \\
\text { of } \\
\text { Shipment }\end{array}$ & $\begin{array}{l}\text { Number } \\
\text { of Fault } \\
\text { Shipment }\end{array}$ & $\begin{array}{l}\text { Correct } \\
\text { shipment } \\
\text { percentage }\end{array}$ & $\begin{array}{l}\text { Average } \\
\text { Quality } \\
\text { Success } \\
\text { level }\end{array}$ \\
\hline S1 & 22 & 9 & $59.09 \%$ & 2169 & 520 & $76.03 \%$ & 13 & 5 & $61.54 \%$ & $65.55 \%$ \\
\hline S3 & 11 & 1 & $90.91 \%$ & 12834 & 540 & $95.79 \%$ & 7 & 1 & $85.71 \%$ & $90.81 \%$ \\
\hline S4 & 28 & 5 & $82.14 \%$ & 167033 & 14980 & $91.03 \%$ & 40 & 6 & $85.00 \%$ & $86.06 \%$ \\
\hline S5 & 71 & 7 & $90.14 \%$ & 2203477 & 242724 & $\mathbf{8 8 . 9 8 \%}$ & 79 & 7 & $91.14 \%$ & $90.09 \%$ \\
\hline S6 & 1 & 1 & $0.00 \%$ & 176000 & 16000 & $90.91 \%$ & 8 & 1 & $87.50 \%$ & $59.47 \%$ \\
\hline
\end{tabular}


Step 4: The software is executed to analyze the available suppliers. For the demonstration of the model, two orders for product $069007 \mathrm{Q} 00$ are created; 01 and 05 . The program was run for the selection of a suitable supplier for another raw material h2 which is required to produce 069007Q00.

As explained earlier, Order Organizer Agent receives the new orders from the user and sends this information to the Material Requirement Agent by means of software communication.

There were two different orders for product 069007Q00. Requested units in o1 are 150, and requested units in o5 are 200. The information that a total of 350 products will be produced reaches Material Requirements Agent. Agent calculates the required units of raw materials. For this product, the order amount is equal to 350 units, depend on the bill of material list, required h2 units are calculated by the software. Then, Agent searches for the available suppliers for the related raw materials depend on the zero stock assumption.

There is one more important decision here, two orders have different due dates, agent considers the order which has minimum due date for the select available supplier (see equation 2). There are 7 suppliers available for supplying h2 as shown in Table IV.

TABLE IV: Searching for Available Supplier for h2

\begin{tabular}{|c|c|}
\hline 1 & $\begin{aligned} \text { Order } & =\text { o1 } \text { Order }=\text { o5, Product }=069007 \mathrm{Q} 00, \\
\text { Material } & =\text { h2, Supplier }=\mathbf{s 1}, \text { Supply Time }=11.0\end{aligned}$ \\
\hline 2 & $\begin{aligned} \text { Order } & =\text { o1, Order }=\text { o5, Product }=069007 \mathrm{Q} 00, \\
\text { Material } & =\text { h2, Supplier }=\mathbf{s 3}, \text { Supply Time }=3.0\end{aligned}$ \\
\hline 3 & $\begin{aligned} \text { Order } & =\text { o1, Order }=\text { o5, Product }=069007 \mathrm{Q} 00, \\
\text { Material } & =\text { h2 Supplier }=\mathbf{s 4}, \text { Supply Time }=5.0\end{aligned}$ \\
\hline 4 & $\begin{array}{r}\text { Order }=\text { o1, Order }=\text { o5, Product }=069007 \mathrm{Q} 00, \\
\text { Material }=\text { h2, Supplier }=\mathbf{s 5}, \text { Supply Time }=4.0\end{array}$ \\
\hline 5 & $\begin{aligned} \text { Order } & =\text { o1 }, \text { Order }=05 \text { Product }=069007 \mathrm{Q} 00 \\
\text { Material } & =\text { h2 } \text { Supplier }=\mathbf{s 8}, \text { Supply Time }=8.0\end{aligned}$ \\
\hline 6 & $\begin{array}{r}\text { Order }=\text { o1, Order }=05, \text { Product }=069007 \mathrm{Q} 00, \\
\text { Material }=\text { h2, Supplier }=\mathbf{s 9}, \text { Supply Time }=5.0\end{array}$ \\
\hline 7 & $\begin{array}{r}\text { Order }=\text { o1, Order }=\text { o5, Product }=069007 \mathrm{Q} 00, \\
\text { Material }=\text { h2, Supplier }=\mathbf{s 1 0} \text { Supply Time }=8.0\end{array}$ \\
\hline
\end{tabular}

TABLE V: Supplier Information for Material h2 with PQPT

\begin{tabular}{|c|c|}
\hline 1 & $\begin{array}{l}\text { Order }=\text { o1, Order }=\text { o5, Product }=069007 \mathrm{Q} 00 \text { Material }= \\
\text { h2, Supplier }=\text { s1, Supply Time }=11.0, \text { Cost }=76.0, \text { Quality } \\
=20.0, \text { Payment Term }=3.0, \text { PQPT }=\mathbf{5 . 6 4}\end{array}$ \\
\hline 2 & $\begin{array}{l}\text { Order }=\text { o1, Order }=\text { o5, Product }=069007 \mathrm{Q} 00 \text { Material }= \\
\text { h2, Supplier }=\text { s3, Supply Time }=3.0, \text { Cost }=121.59, \text { Quality } \\
=90.0, \text { Payment Term }=0.0, \text { PQPT }=\mathbf{2 3 . 4 1}\end{array}$ \\
\hline 3 & $\begin{array}{l}\text { Order }=\text { o1, Order }=\text { o5, Product }=069007 \mathrm{Q} 00 \text { Material }= \\
\text { h2, Supplier }=\text { s4, Supply Time }=5.0, \text { Cost }=197.6 \text {, Quality }= \\
\text { 90.0, Payment Term }=1.0, \text { PQPT }=\mathbf{2 3 . 5 4}\end{array}$ \\
\hline 4 & $\begin{array}{l}\text { Order }=\text { o1, Order }=\text { o5, Product }=069007 \mathrm{Q} 00, \text { Material }= \\
\text { h2, Supplier }=\text { s5, Supply Time }=4.0, \text { Cost }=380.0, \text { Quality }= \\
\text { 85.0, Payment Term }=2.0, \text { PQPT }=\mathbf{2 3 . 6 8}\end{array}$ \\
\hline 5 & $\begin{array}{l}\text { Order }=\text { o1, Order }=\text { o5, Product }=069007 \mathrm{Q} 00, \text { Material }= \\
\text { h2, Supplier }=\text { s8, Supply Time }=8.0, \text { Cost }=167.19, \text { Quality } \\
=90.0, \text { Payment Term }=1.0, \text { PQPT }=\mathbf{2 3 . 5 4}\end{array}$ \\
\hline 6 & $\begin{array}{l}\text { Order }=\text { o1, Order }=\text { o5, } \text { Product }=069007 \mathrm{Q} 00, \text { Material }= \\
\text { h2, Supplier }=\mathrm{s} 9, \text { Supply Time }=5.0, \text { Cost }=273.6, \text { Quality }= \\
\text { 80.0, Payment Term }=1.0, \mathrm{PQPT}=\mathbf{2 0 . 9 4}\end{array}$ \\
\hline 7 & $\begin{array}{l}\text { Order }=\text { o1, Order }=\text { o5, Product }=069007 \mathrm{Q} 00, \text { Material }= \\
\text { h2, Supplier }=\text { s10, Supply Time }=8.0, \text { Cost }=170.24, \\
\text { Quality }=90.0, \text { Payment Term }=0.0, \text { PQPT }=\mathbf{2 3 . 4}\end{array}$ \\
\hline
\end{tabular}

As shown in Table IV, available suppliers for raw material h2 are 1, 3, 4, 5, 8, 9, and 10. The agent sends this information to the procurement agent for calculating PQPT values by also using AHP decision tool. Table V includes this information.

As can be seen by this analysis, the best Suppliers by PQPT is $s_{5}$ with the following information.

\footnotetext{
Order $=o_{1}$, Order $=0_{5}$, Product $=069007 Q 00$, Material $=h_{2}$, Supplier $=s_{5}$, Supply Time $=4.0$, Cost $=380.0$, Quality $=$ 90.0, Payment Term $=$ 2.0, $\mathrm{PQPT}=23.68$
}

The procurement agent sends this information to the Buyer Agent. It then, sends a request to Supplier Performance Assessor to receive the values of the opportunity costs. Supplier Performance Assessor, on the other hand, calculates the opportunity cost of each purchasing alternative which has more or less the same PQPT values (S3, S4, S5, and S8). Results of calculation are given in Table VI. 
TABLE VI: Opportunity costs of the suppliers for material $\mathrm{h}_{2}$

\begin{tabular}{|c|c|}
\hline 1 & $\begin{array}{c}\text { Order }=\text { o1, Order }=\text { o5, Product }=069007 \mathrm{Q} 00, \text { Quantity } \\
=350.0, \text { Material }=\mathrm{h} 2, \text { Raw Quantity }=350, \text { Supplier }=\mathbf{s 3} \text {, } \\
\text { Supply Time }=3.0, \text { Cost }=121.59, \text { Quality }=90.0, \text { Payment } \\
\text { Term }=0.0, \text { PQPT }=23.41, \text { Opportunity Cost }=\mathbf{0 . 0}\end{array}$ \\
\hline 2 & $\begin{array}{l}\text { Order }=\text { o1, Order }=\text { o5, Product }=069007 \mathrm{Q} 00 \text {, Quantity } \\
=350.0 \text {, Material }=\text { h2, Raw Quantity }=350, \text { Supplier }=\mathbf{s 4} \text {, } \\
\text { Supply Time }=5.0, \text { Cost }=197.6, \text { Quality }=90.0, \text { Payment } \\
\text { Term }=1.0, \text { PQPT }=23.54, \text { Opportunity Cost }=\mathbf{1 1 5 2 . 6 6}\end{array}$ \\
\hline 3 & $\begin{array}{l}\text { Order }=\text { o1, Order }=\text { o5, Product }=069007 \mathrm{Q} 00, \text { Quantity } \\
=350.0, \text { Material }=\mathrm{h} 2, \text { Raw Quantity }=350, \text { Supplier }=\mathbf{s 5} \text {, } \\
\text { Supply Time }=4.0, \text { Cost }=380.0, \text { Quality }=90.0, \text { Payment } \\
\text { Term }=2.0, \text { PQPT }=23.68, \text { Opportunity Cost }=\mathbf{4 4 3 3 . 3 3}\end{array}$ \\
\hline 4 & $\begin{array}{c}\text { Order }=\text { o1, Order }=\text { o5, Product }=069007 \mathrm{Q} 00, \text { Quantity }= \\
\text { 350.0, Material }=\text { h2, Raw Quantity }=350, \text { Supplier }=\mathbf{s 8} \text {, } \\
\text { Supply Time }=8.0, \text { Cost }=167.19, \text { Quality }=90.0, \text { Payment } \\
\text { Term }=1.0, \text { PQPT }=23.54, \text { Opportunity Cost }=\mathbf{9 7 5 . 3 3}\end{array}$ \\
\hline
\end{tabular}

S5 is also the best supplier based on opportunity cost calculation;

Order $=o_{1}$, Order $=o_{5}$, Product $=069007 Q 00$, Quantity $=350.0$, Material $=h_{2}$, Raw Quantity $=350$, Supplier $=s_{5}$, Supply Time $=4.0$, Cost $=380.0$, Quality $=90.0$, Payment Term $=2.0$, PQPT $=23.68$, Opportunity Cost $=4433.33$

Supplier Performance Assessor sends this information to the Buyer Agent. All this calculations shows that S5 is the most appropriate supplier to purchase h2. Buyer agent sends a procurement order to this supplier. The Supplier Performance Assessor also sorts the PQPT values from bigger to smaller using the following classification and records the new success value for $\mathrm{h} 2$ in each supplier card is calculated using the following rules.

- On the supplier's card of Supplier which has the highest PQPT value, change the h2 success rate to 1,

- On the supplier's card of Supplier which has the second highest PQPT value, change the h2 success rate to 2 ,

- Go on until all supplier h2 success values are updated.

The following formula is used to calculate the overall percentage of success for each supplier after new updates.

Overall Success = Sum of all PQPT Sequence values for all materials sold by the supplier / Number of materials sold by the supplier (see last column of Appendix A)

Results of this calculation are interpreted as the following.

If overall success $=1$ then, respective supplier success rate is $100 \%$

If overall success is between 1.01 and 2.00 then, respective supplier success rate is $80 \%$

If overall success is between 2.01 and 3.00 then, respective supplier success rate is $60 \%$

If overall success is between 3.01 and 4.00 then, respective supplier success rate is $40 \%$

If overall success is between 4.01 and 5.00 then, respective supplier success rate is $20 \%$

If overall success is greater than 5.01 then, respective supplier success rate is $0 \%$

Suppose that, three different products are supplied by supplier S5 namely, h2, h4 and h5. After every procurement process, total success value must be recalculated. Total success value can then be calculated based on the classification defined by Supplier Performance Assessor. If;

$>$ success of h2 calculated as 1 ;

$>$ success of $\mathrm{h} 4$ was 2 ;

success of h5 was 3 :

Total success rate of S5 calculated as: $(\mathbf{1 + 2 + 3}) / \mathbf{3}=\mathbf{2}$

That means, the success level of $\mathrm{s} 5$ is $80 \%$. 
Suppose success level of all suppliers is calculated as the following.

$\begin{array}{ll}\text { S1: Company A } & 80.00 \% \\ \text { S2: Company B } & 60.00 \% \\ \text { S3: Company C } & 40.00 \% \\ \text { S4: Company D } & 60.00 \% \\ \text { S5: Company E } & 80.00 \% \\ \text { S8: Company F } & 60.00 \% \\ \text { S9: Company G } & 80.00 \% \\ \text { S10: Company H } & 40.00 \%\end{array}$

Then, the Average Success Rate of the calculated by the model for all suppliers is $62.5 \%$

Case study results indicate that the company must be improved their Suppliers list. Up to now, execution of the model is explained. The proposed model is also simulated for different pieces and the effect of the results is examined. As can be seen from the Figure 11, the proposed model has provided a significant decrease in procurement cost. Also, it is seen that when the purchased quantity increase, the decrease rate of the model on purchasing cost is increasing.

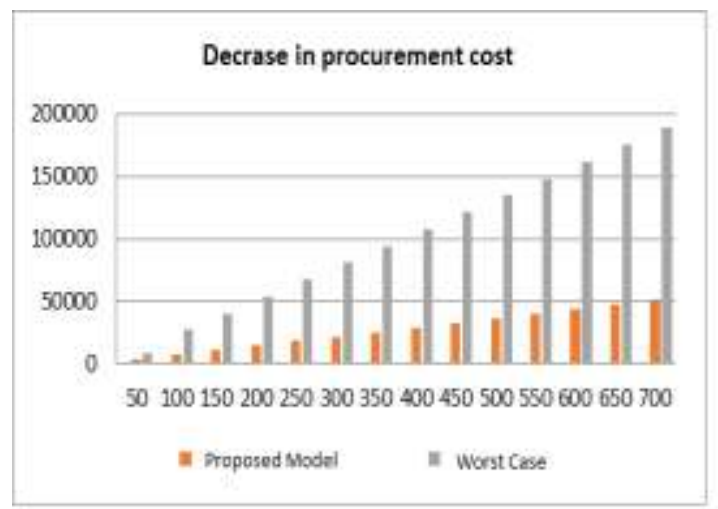

Fig. 11: Some of the simulation results conducted on procurement cost (in terms of \$)

\section{Conclusion}

In this study, it was focused on possibility of using agent based system for supplier selection problem in order to increase automation and autonomy for the sake of productivity as well as efficient decision making on suppliers. This study differs from previous work in twofold. First, the model takes the payment term into consideration. And second, in addition to the performance measurement of a specific supplier, it gives the ability to measure how well the company selection process is implemented. The results of the case study, clearly indicated that the supplier selection capability of company $\mathrm{ABC}$ is increased while the procurement is decreasing.

The study will continue with the following objectives;

- Although agent adaptation and agent learning is stated in the model, a multi-agent learning should be developed in order to increase the level of integration between different modules.

- A more systematic way to define the weight values are to be defined.

- Continue to extend the current prototype to all manufacturing functionalities.

- Integrating the model within the framework of Industry 4.0 is yet to be investigated. 


\section{References}

[1] De Boer, L., Labro, E., \& Morlacchi, P. (2001). A review of methods supporting supplier selection. European Journal of Purchasing \& Supply Management, 7(2), 75-89.

https://doi.org/10.1016/S0969-7012(00)00028-9

[2] Wooldridge, M., \& Jennings, N. R. (1995). Intelligent agents: Theory and practice. The knowledge engineering review, 10(02), 115-152.

https://doi.org/10.1017/S0269888900008122

[3] O'Hare, G. M., \& Jennings, N. (1996). Foundations of distributed artificial intelligence (Vol. 9). John Wiley \& Sons.

[4] Swaminathan, J. M., Smith, S. F., \& Sadeh, N. M. (1998). Modeling supply chain dynamics: A multiagent approach. Decision sciences, 29(3), 607-632.

https://doi.org/10.1111/j.1540-5915.1998.tb01356.x

[5] Caridi, M., \& Cavalieri, S. (2004). Multi-agent systems in production planning and control: an overview. Production Planning \& Control, 15(2), 106-118.

https://doi.org/10.1080/09537280410001662556

[6] Chan, F. T. S., \& Chan, H. K. (2004). A new model for manufacturing supply chain networks: A multiagent approach. Proceedings of the Institution of Mechanical Engineers, Part B: Journal of Engineering Manufacture, 218(4), 443-454.

https://doi.org/10.1243/095440504323055551

[7] Nissen, M. E. (2001). Agent-based supply chain integration. Information Technology and Management, 2(3), 289-312. https://doi.org/10.1023/A:1011449109160

[8] Mohebbi, S., \& Li, X. (2012). Designing intelligent agents to support long-term partnership in two echelon e-Supply Networks. Expert Systems with Applications, 39(18), 13501-13508.

https://doi.org/10.1016/j.eswa.2012.07.008

[9] Kim, H. S., \& Cho, J. H. (2010). Supply chain formation using agent negotiation. Decision Support Systems, 49(1), 77-90. https://doi.org/10.1016/j.dss.2010.01.004

[10] Wang, G., Wong, T. N., \& Wang, X. (2013). An ontology based approach to organize multi-agent assisted supply chain negotiations. Computers \& Industrial Engineering, 65(1), 2-15. https://doi.org/10.1016/j.cie.2012.06.018

[11] Wang, X., T. Wong, and G. Wang. (2012), “An Ontological Intelligent Agent Platform to Establish an Ecological Virtual Enterprise.” Expert Systems with Applications 39 (8): 7050-7061.

https://doi.org/10.1016/j.eswa.2012.01.042

[12]Wong, T. N., \& Fang, F. (2010). A multi-agent protocol for multilateral negotiations in supply chain management. International Journal of Production Research, 48(1), 271-299.

https://doi.org/10.1080/00207540802425393

[13]Fang, F., \&Wong, T. N. (2010). Applying hybrid case-based reasoning in agent-based negotiations for supply chain management. Expert Systems with Applications, 37, 8322-8332.

https://doi.org/10.1016/j.eswa.2010.05.052

[14] Wang, G., T. N. Wong, and X. Wang. (2014). "A Hybrid Multi-agent Negotiation Protocol Supporting Agent Mobility in Virtual Enterprises.” Information Sciences 282: 1-14.

https://doi.org/10.1016/j.ins.2014.06.021 
[15] Yu, F., T. Kaihara, N. Fujii, C. Sun, and W. Yang. (2015). "A Multi-attribute Multi-item Negotiation Mechanism of Supply Chain Networks between Buyers and Sellers.” International Journal of Production Research 53 (20): 6143-6160 https://doi.org/10.1080/00207543.2015.1034328

[16] He, Z., Wang, S. Y., \& Cheng, T. C. E. (2013). Competition and evolution in multiproduct supply chains: An agent-based retailer model. International Journal of Production Economics, 146(1), 325-336 https://doi.org/10.1016/j.ijpe.2013.07.019

[17]Russ, C., \& Walz, A. (2009, September). MACSIMA: Simulating the co-evolution of negotiation strategies in agent-based supply networks. In Web Intelligence and Intelligent Agent Technologies, 2009. WI-IAT'09. IEEE/WIC/ACM International Joint Conferences on (Vol. 2, pp. 44-51). IEEE.

[18] Akanle, O. M., \& Zhang, D. Z. (2008). Agent-based model for optimising supply-chain configurations. International Journal of Production Economics, 115(2), 444-460

https://doi.org/10.1016/j.ijpe.2008.02.019

[19] Taha H. A., (2007). Operations research: an introduction,Vol. 557. Pearson/Prentice Hall.

APPENDIX A.Pre-defined Supllier Card - ( for Supplier S5)

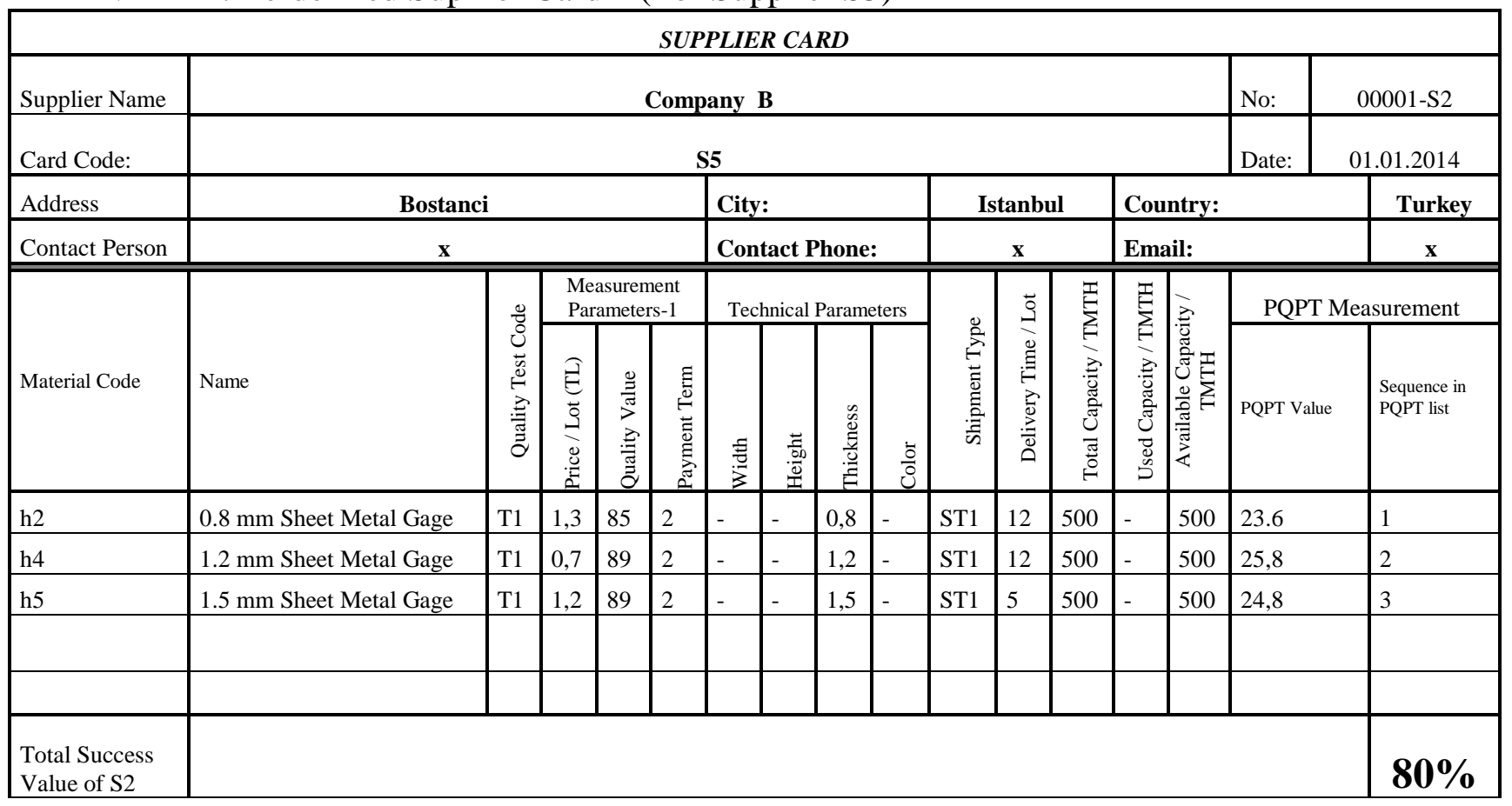

